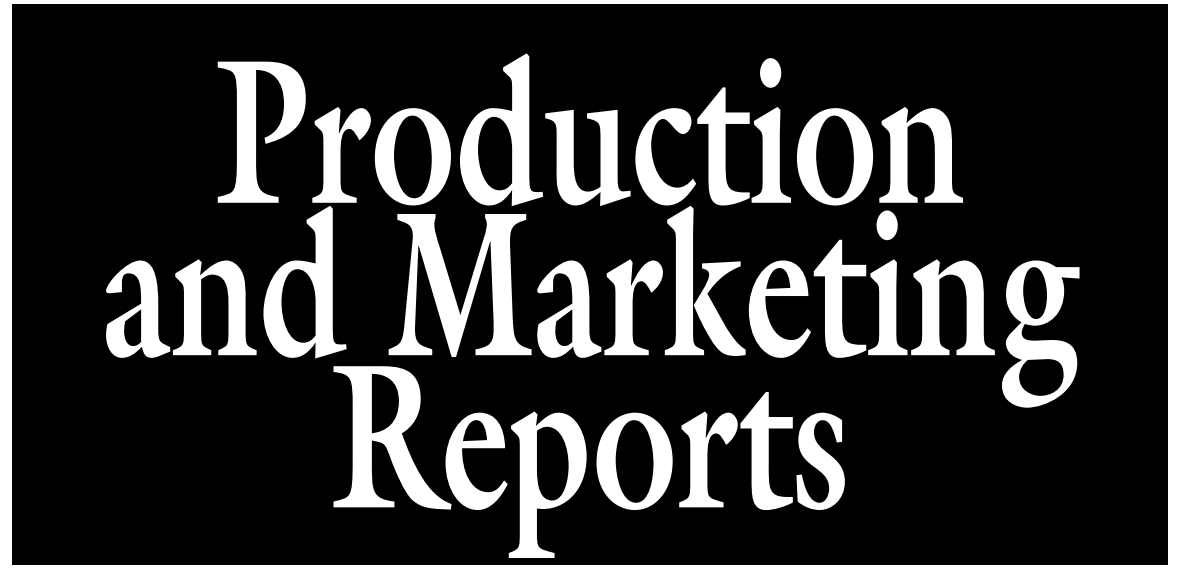

\section{The Impact of Technology on Labor Makeup: A Study of the Green Industry}

\author{
Joseph Krahe ${ }^{1}$ and Benjamin Campbell ${ }^{2,3}$
}

ADDITIONAL INDEX WORDs. employment, propensity score matching, part-time labor, full-time labor

SUMMARY. Green industry is in a state of rapid change and turmoil as it reacts to the 2008 financial crisis and its arrival at maturity. In an effort to survive this challenging period, many firms are using new technologies, ranging from basic e-mail and accounting software to sophisticated digital imaging systems for identifying diseases. However, there has been a noteworthy lack of research into the way that technology adoption impacts labor in this industry. This paper uses propensity score matching (PSM) to identify the impact that various technologies have on the number of full- and part-time employees as well as the portion of full-time laborers that green firms employ. We find that none of the technologies studied had a significant impact on the percentage of full-time workers employed by green industry firms, but there were some effects when examining full-time, part-time, and total number of workers.

$\mathrm{I}$ n 2007-08, direct employment in the green industry was estimated as 1.2 million, of which almost $22 \%$ was devoted to production-related tasks (Hodges et al., 2011). As noted by Posadas (2012), laborers in the green industry "perform varied functions and are subjected to different working conditions." Workers do a myriad of tasks such as pruning, applying fertilizers, planting, harvesting,

This research was supported in part by a grant from the Horticulture Research Institute, Washington, DC as well as funding from the USDA multistate project S-1065 under USDA-NIFA. Multi-state project S-1065, also termed the Green Industry Consortium is a multi-state Research Committee of agricultural economists and horticulturists in the United States.

${ }^{1}$ Department of Agricultural and Resource Economics, University of Connecticut, 1376 Storrs Road Unit 4021, Storrs, CT 06269

${ }^{2}$ Department of Agricultural and Applied Economics, University of Georgia, 314-A Conner Hall, The University of Georgia, Athens, GA 30602

${ }^{3}$ Corresponding author. E-mail: bencamp@uga.edu. much growers would save on human labor" (Jones, 2013).

In a broad context, labor studies have tended to focus on demand for migrant workers and its impact on legal/illegal immigration (Cross et al., 2008; Preibisch, 2010; Rogaly, 2008). With respect to the green industry, Behe et al. (2013) noted that "it is essential for green industry firms to understand the impact of new technologies on their business." However, as noted by Bellenger et al. (2008), there are few studies that address labor issues in the green industry. Existing studies include characteristics of the workforce (Posadas et al., 2014), adoption of labor (Caplan et al., 2014), and economic impacts of technology adoption (Posadas, 2012). With respect to how technology impacts labor, Posadas (2012) finds a neutral labor impact to the level of mechanization. However, the Posadas' (2012) study does not examine the impact of individual technologies.

This paper aims to fill this gap by examining how varying types of technology usage impact full-time, parttime, and total labor as well as labor makeup within green industry firms. The literature on this topic is mixed. Hitt and Snir (1999) point out that technology can have a substitution effect on labor such that:

the value [of technology] was generally viewed in terms of labor substitution; by using computers an organization could automate data storage and retrieval, conduct routine transaction processing and improve organizational communications. This reduces the need for file clerks, accountants and even middle managers, who traditionally performed those functions.

However, Jupe and Hall (2002) note that there may be a complementary relationship between increasing automation in manufacturing plants and service firms as workers are given more flexible job assignments. If this is the case within the green industry, we should expect to see either no difference in employment levels of technology users and nonusers or increased levels for technology users due to potential cost savings from technology.

Our hypothesis was that certain types of technologies \{i.e., computerized landscape designing [computeraided design (CAD)], production scheduling, digital imaging for disease 
diagnosis, greenhouse production controls, inventory management, and bar coding\} will have a substitution effect (i.e., reduce the need for part-time workers at a firm). Notably, technologies that could replace labor-intensive tasks would result in need for less parttime workers in favor of potentially higher skilled jobs that would most likely be filled by full-time employees. In contrast, we hypothesize that some types of technologies [i.e., word processing, accounting, financial investment, internet commerce, marketing compact discs (CDs), and e-mail] will have a neutral or positive effect on the employment (number or makeup) within green industry firms.

\section{Materials and methods}

The primary source of data for this research was the 2009 National Nursery Survey, conducted by the Green Industry Research Consortium. Although the survey was conducted in 2009 , the information refers to business activity took place in 2008. A detailed account of the survey sampling methodology can be found in Hall et al. (2011); however, a brief synopsis is given here. First, a list of roughly 38,000 firms operating in the green industry were compiled from all 50 states based on information from the National Plant Health Board, state nursery associations, and the OneSource business directory. To provide some perspective, the 2007 U.S. Census of Agriculture lists the total number of firms in the nursery/greenhouse industry as 50,784 (U.S. Department of Agriculture, 2007).

Once this list was compiled, a stratified random sample was used. Firms were placed into one of four size classes based on open production area, greenhouse area, or the number of units they had in inventory. A total of 14,964 firms were selected to receive surveys through the mail. This represented $100 \%$ of large firms, $60 \%$ of medium firms, $32 \%$ of small firms, $20 \%$ of very small firms, and $45 \%$ of firms for which the size was unknown (Hall et al., 2011). The aim of this distribution was to capture a larger portion of the firms that had a significant output, which tend to be the major players in the industry. After correcting for faulty addresses, a total of 14,123 firms were actually mailed surveys.

In addition to the mail survey, 2896 firms received an electronic survey

Table 1 . Technology utilization in 2008 by green industry firms as found by the 2009 National Nursery Survey, conducted by the Green Industry Research Consortium.

\begin{tabular}{lc}
\hline Technology $^{\mathrm{z}}$ & Mean $(\mathbf{\%})^{\mathbf{y}}$ \\
\hline Word processing & 0.579 \\
Accounting/cost analysis & 0.522 \\
Inventory management & 0.355 \\
Financial investments/analysis & 0.248 \\
Internet commerce (B2B or B2C) & 0.224 \\
CDs for marketing & 0.082 \\
Communications: e-mail & 0.546 \\
Landscape designing (CAD) & 0.055 \\
Production scheduling & 0.148 \\
Greenhouse production controls & 0.084 \\
Digital imaging for disease diagnosis & 0.041 \\
Bar coding & 0.085 \\
Other functions & 0.035 \\
\hline
\end{tabular}

${ }^{\mathrm{z}} \mathrm{B} 2 \mathrm{~B}$ = business to business; $\mathrm{B} 2 \mathrm{C}=$ business to consumer; $\mathrm{CD}=$ compact disc; CAD = computer-aided design. yercentage of firms within the sample using the technology.

through e-mail. This was the first time that the Greenhouse Industry Research Consortium used such a methodology, and the online survey was distributed to all firms that had an e-mail address readily available. In combination with the traditional surveys, the use of e-mail resulted in a total of 17,019 firms being assessed. Consequently, $45 \%$ of the nursery firms in the United States were provided the survey with an overall response rate of $17.9 \%$ (Hall et al., 2011).

The survey asked questions on a host of topics from production to marketing. This study is focused on the number of permanent employees, the number of temporary or seasonal employees, and which, if any, of the 13 listed technologies that the firm used (Table 1). These variables can be broadly divided into two categories: technologies that are not specific to the green industry (e.g., word processing and e-mail) and those that are primarily used in the green industry (e.g., computerized landscape design and computerized greenhouse controls). Other variables of interest included the types of products a firm sold, the percent of sales that were negotiated, the percent of sales to wholesale, ratings of factors for determining prices for products, and the year the firm was established. Summary statistics for variables included in the analysis can be found in Table 2 .

In addition to characteristics of the individual firms, it was desirable to include some general demographic data about the region where the firms were located. For this purpose, census data were incorporated to supplement the information from the National
Nursery Survey. Variables, such as the percentage of males and the percent of the population that was Caucasian, at the zip code level were drawn from the most recent 2010 census and merged into the dataset. Once these variables had been incorporated, the final dataset was established.

Propensity score matching. The method that was used to estimate the impact of technology implementation on labor number and makeup in the green industry was propensity score matching (PSM). PSM has a long history of use in economics (Bryson et al., 2002; O'Keefe, 2004), healthcare (Aksoy et al., 2007; Hirano and Imbens, 2001), and policy analysis (Campbell et al., 2011; Heckman and Hotz, 1989). In a broad sense, PSM allows for the comparison of treatment groups by creating a counterfactual such that groups are identical across all factors except the treatment group. It is appropriate to use PSM when the differences between treatment groups are likely not to be caused exclusively of the treatment. In the case of this study, treatment assignment was based on whether an individual firm used a given technology or not. So, if firms over a certain size are the only ones that use a technology, then failure to account for this relationship can cause biased results. PSM allows for like firms that use and do not use a technology to be compared.

It is almost certain that firm characteristics aside from the use of technology had an impact on the makeup of the labor force for any given firm. Failure to account for important factors would 
Table 2. Summary statistics from the 2009 National Nursery Survey (conducted by the Green Industry Research Consortium) for variables used in the logit model to calculate propensity scores.

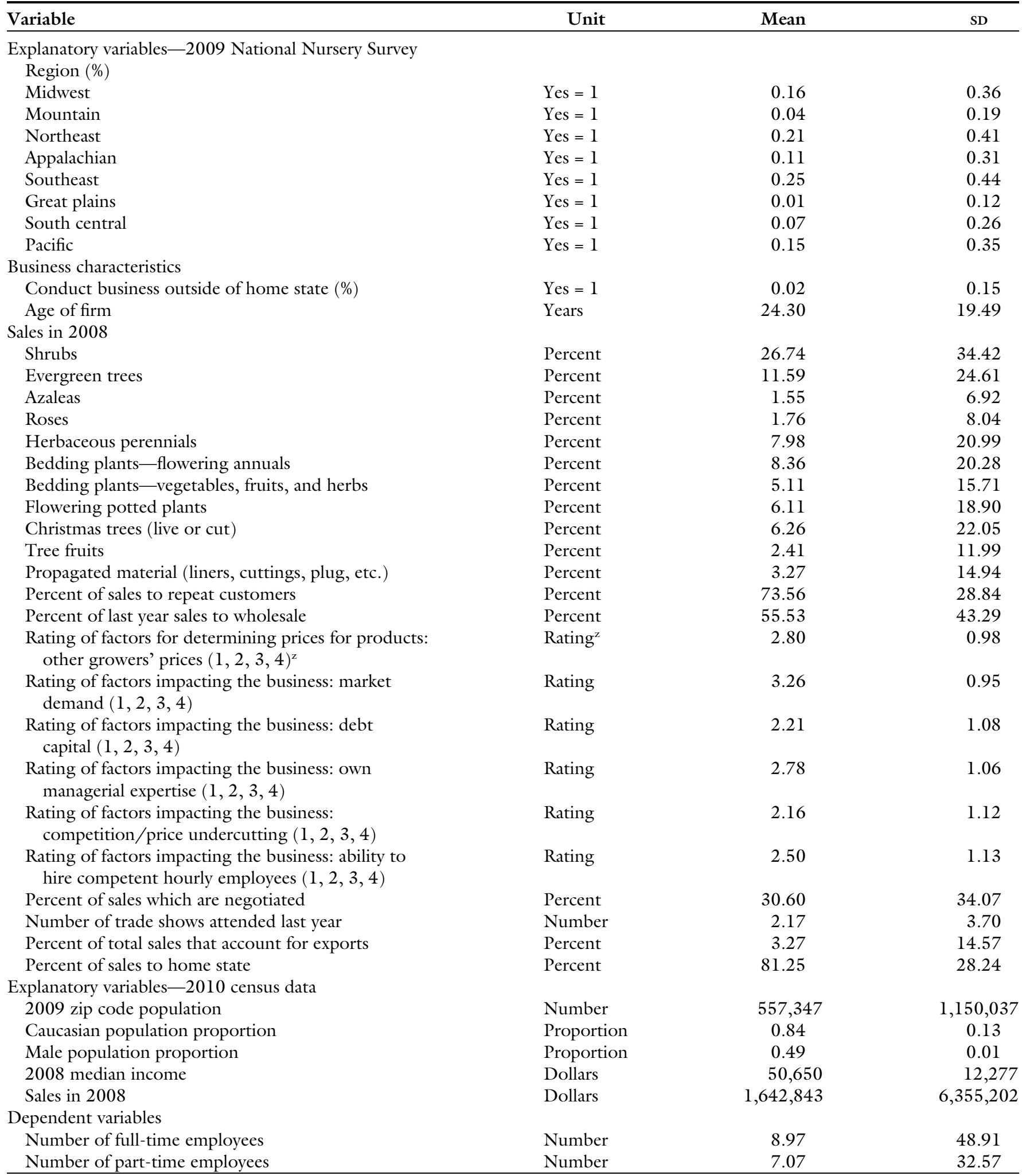

${ }^{\mathrm{z}} \mathrm{l}$ = not important; 2 = minor importance; 3 = important; 4 = very important.

have resulted in biased or inconsistent estimates (Foster, 2003). Some obvious variables that were likely to impact the composition of labor for a firm included the firm's sales revenue (as an indicator of a firm's size), the population characteristics around the firms production location (zip code characteristics of area), and the type of goods they produced and/or sold (an indicator of what types of labor are needed as some crops are more labor intensive). 
Rosenbaum and Rubin (1984) laid out the framework for using PSM in observational studies to accommodate nonrandomization of treatment group assignment. The first step in PSM is to estimate a probit or logit model (logit in the case of this study), which calculates the likelihood that each observation (firm) will be assigned into the treatment group based on the independent variables associated with that firm. Mathematically, this is conveyed as:

$$
P(x)=\operatorname{prob}(D=1 \mid x)=E(D \mid x)
$$

where $P(x)$ is the conditional probability that a given observation will be assigned to the treatment group based on $x$, a vector of independent variables. $D$ is the dependent variable, equal to one if an individual is in the treatment group (Katchova, 2010). The variables used in the logit models were chosen after evaluation of previous literature as well as variables deemed important by the researchers. In picking the final set of variables to be included in the logit models for each technology, we satisfied the balancing criteria for each model. In satisfying the balancing criteria, some models had more/less variables depending on which set of variables satisfied the balancing criteria while also maximizing the hit-or-miss and pseudo $r^{2}$ guidelines set forth by Heckman et al. (1997) that help assess the reliability of the propensity scores. The results of the logit models results (and the corresponding marginal effects) are available from the corresponding author or via an online appendix (Supplemental Tables 1-14) on the author's departmental website.

Once each observation has been assigned a propensity score, it allows for the matching of observations based on similar scores, as opposed to matching based on individual variables (e.g., sales revenue, percent of sales to wholesale). To satisfy the conditional mean independence assumption, it is sometimes necessary to remove certain confounding variables to meet the balancing condition, thereby reducing the impact of confounding variables within the analysis (Dehejia and Wahba, 1999). Therefore, the variables that were used as matching criteria occasionally changed between the models. The variables that were used for matching are shown in Table 2 .

The overall idea of PSM is to match an observation within the treatment group with a similar observation(s) that is not in the treatment group in an effort to get an estimate of the impact of the treatment on the dependent variable. This difference is referred to as the average treatment effect on the treated (ATT) and is represented as follows:

$$
\mathrm{ATT}=E\left(\Upsilon_{i}^{\mathrm{T}}-\Upsilon_{i}^{\mathrm{C}} \mid D=1\right)
$$

where $\Upsilon_{i}^{\mathrm{T}}$ is the value of the dependent variable for the treatment group $\Upsilon_{i}^{\mathrm{C}}$ is the value of the dependent variable for the control group, and $D$ is a binary variable equal to one if an observation received the treatment (Katchova, 2010). In addition to the ATT, we also obtained the Rosenbaum bound (r-bound) for each ATT, which is a measurement of robustness. The $r$-bound for a given model assesses the necessary impact of bias coming from a confounding variable(s) that would alter the significance of a finding (Rosenbaum, 2002). For instance, what impact would a variable not in the model have to have to change the significance of the results.

Once the balancing property was satisfied and propensity scores were calculated, several matching algorithms were used to assess differences between use and nonuse of the technologies. Matching algorithms use different methods to compare observations within the treated group to an observation(s) within the untreated group, see Becker and Inchino (2002) for more information. For this study, we used kernel matching, nearest neighbor matching, and radius matching (using all observations within a defined radius - three different radiuses were used). STATA (version 13.1; StataCorp, College Station, TX) was used to test different matching algorithms for every technology. Using percent bias reduction as an indicator of performance, we report the findings of the radius matching, with replacement, common support and a 0.1 radius as it had the highest bias reduction across models, see Supplemental Table 14 (available on the author's departmental website) for bias reduction statistics. With respect to radius matching with a 0.1 radius, only those untreated observations with a propensity score within a 0.1 range around the treated observation's propensity score were compared with the treated observation.

\section{Results and discussion}

The results of the PSM indicated that overall technology had little to no impact on employment levels. However, we do see a couple of specific technologies impacting employment significantly but in different ways.

Full-time LABOR. With respect to full-time labor, we find that accounting/cost analysis and financial/ investment technologies increase the number of full-time workers by 4.87 and 5.54 workers, respectively (Table 3 ). Keep in mind that the PSM mechanism is matching like firms together. For instance, PSM is matching firms in different treatment groups (i.e., with and without technology) that have similar sales, types of plants being produced, zip code characteristics, etc. to have a robust comparison across treatment groups. Based on the PSM results, the higher number of full-time workers associated with accounting and financial management seems to indicate that firms using these technologies may have their own accounting/financial departments. Given the r-bounds, the financial/investment is more robust to an outside factor not being included in the PSM model based on the higher (1.68) r-bound.

Part-time labor. The part-time worker model also provides some interesting results (Table 3 ). Firms using word processing, accounting/ cost analysis, inventory management, and greenhouse production controls have higher number of part-time workers than firms that do not use the technologies. The accounting/ cost analysis results could point to these firms having dedicated departments that have a combination of fulland part-time workers. However, firms with greenhouse production control technologies have 14 more part-time workers than firms without the production controls.

Total LABOR. With respect to overall employment, firms using technologies for accounting/cost analysis, inventory management, financial/ investment analysis, and greenhouse production controls had higher total employment compared with firms that are not using these technologies 


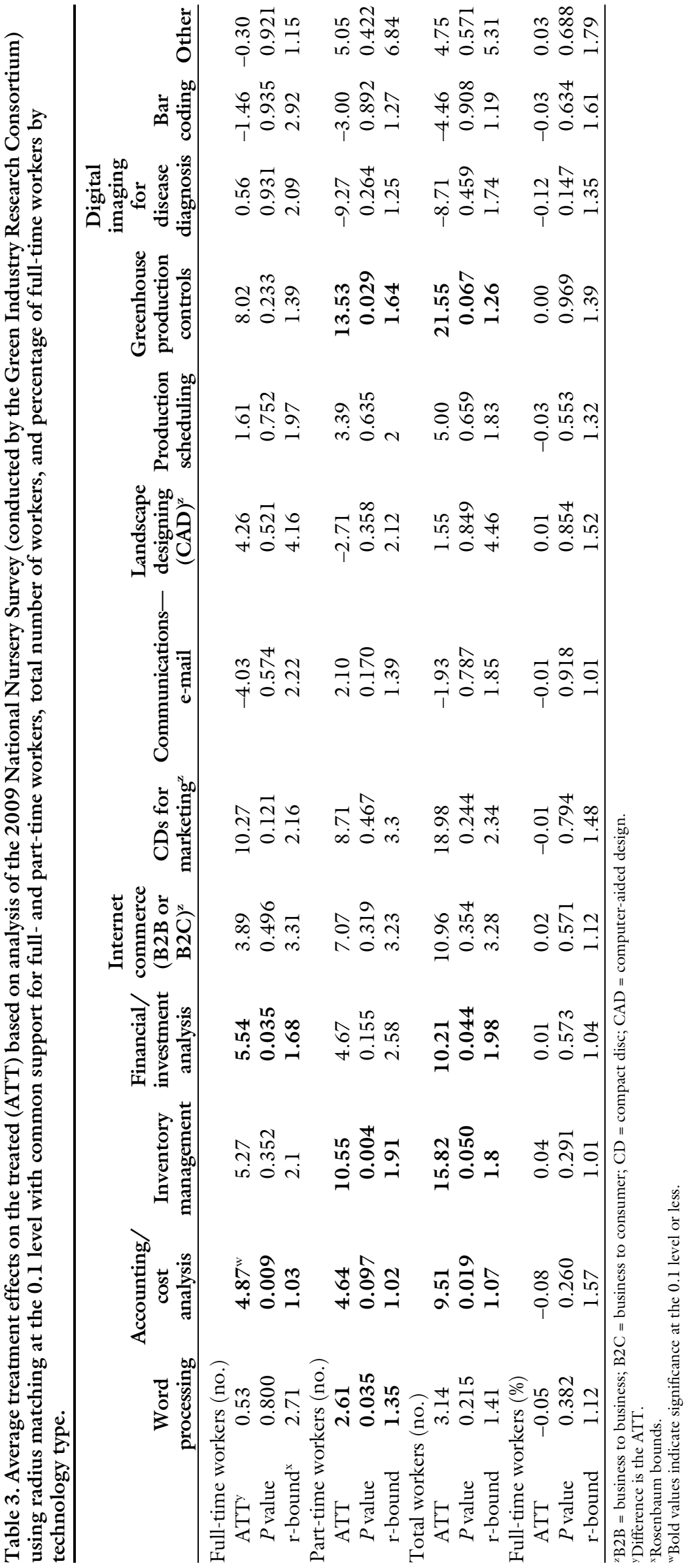

(Table 3). Given that assumptions of PSM were satisfied and the "best" matching algorithm was used, we can have more confidence that our results are an accurate representation of the technologies' impacts on employment. On the basis of this outcome, the employment gain in accounting/cost analysis is most likely coming from a combination of full- and part-time labor as can be seen by the significant results in the full- and part-time worker models. However, for inventory management and greenhouse production controls, we find that the gain in employment is most likely coming from part-time workers. In contrast, the gains in total employment associated with financial/ investment analysis is most likely coming from increases in the number of full-time workers.

LABOR MAKEUP. The results of the PSM indicated that in all cases, the use of a given technology did not significantly impact the labor makeup of a firm (Table 3). Even though we see some technologies having increased full- or part-time numbers, the labor makeup of the firm with and without a technology remains statistically the same. Based on this finding, we can conclude that technology is not displacing parttime workers for full-time workers. In contrast, our findings indicate that firms tend to add more labor for certain technologies, but in a way that causes the percentage of fulland part-time workers to remain unchanged.

IMPACT OF RESULTS. The findings for accounting/cost analysis and financial/investment analysis are what we hypothesized. Our expectation and the results of study indicate that these technologies would have a neutral or positive effect on total employment. Furthermore, we expected greenhouse production control usage would have a substitution effect for part-time labor. However, we observe that firms with these greenhouse production controls have a higher number of part-time workers, which implies a complimentary effect is present. The increase in workers is most likely due to firms receiving efficiencies from the technology and, thereby, are able to hire more parttime workers. Based on these results, our findings are in-line with those of Posadas (2012) "that technology 
adoption by wholesale nurseries and greenhouses [does] not replace any worker[s]."

When examining labor makeup, we find that using a given technology does not allow one type of labor to be used as a substitute for another. Rather, we see the percentage of fullto part-time employees remaining constant. However, a firm's motivation to maximize profit suggests that the adoption of a technology must have some impact on the internal decision processes of labor management in the firm. Most likely the labor makeup stays the same given the technology creates efficiencies in production (i.e., increased yield) or costs so as to allow for the hiring of new workers or the reallocation of workers to other positions within the firm.

\section{Conclusions}

The green industry has a significant impact on the national economy, and an even more drastic impact on local economies. However, this industry, which has undergone tremendous growth and change in the past several decades, has not received adequate attention from researchers. Specifically, the relationships between the technologies used by horticultural firms and their labor composition choices have only been sparingly addressed in the academic literature. This paper has sought to explore and quantify these relationships.

Using the 2009 National Nursery Survey, we were able to examine the employment effects of various technologies on green industry firms. Understanding the role of labor and technology and how these two factors of production interact is essential for firms and policymakers throughout the United States. Our results indicate that technologies are not substitutes for full- or part-time labor, but rather for some technologies have a complimentary effect. However, we find no significant change in the makeup of the work force as the percentage of full- and part-time workers remains constant. From a managerial application perspective, our results are counterintuitive as to what we would expect from an introduction of technology, notably the elimination of labor. Notably technologies seem to offer efficiencies in the production process that allow labor (full- and part time) to be shifted to other production activities within the business. Based on this result, on average, firms having many of these technologies are finding new ways to use their labor to help their business.

This work also provides results that can be used by national, state, or municipal level policymakers that are working to enhance their communities. Policies, grant decisions, etc. that work to increase technology usage by green industry firms to make them more competitive in the face of a mature and increasingly competitive marketplace should focus on the business benefits of technology and less on potential labor implications.

\section{Literature cited}

Aksoy, O., D.J. Sexton, A. Wang, P.A. Pappas, W. Kourany, V. Cu, V.G. Fowler, Jr., C.W. Woods, J.J. Engemann, G.R. Corey, T. Harding, and C.H. Cabell. 2007. Early surgery in patients with infective endocarditis: A propensity score analysis. Clin. Infect. Dis. 44(3):364372 .

Becker, S.O. and A. Inchino. 2002. Estimation of average treatement effects based on propensity scores. Stata J. 2(4): 358-377.

Behe, B.K., B.L. Campbell, C.R. Hall, H. Khachatryan, J.H. Dennis, and C. Yue. 2013. Smartphone use and online search and purchase behavior of North Americans: Gardening and non-gardening information and products. HortScience 48:209-215.

Behe, B.K., J.H. Dennis, C.R. Hall, A.W. Hodges, and R.G. Brumfield. 2008. Regional marketing practices in U.S. nursery production. HortScience 43:2070 2075.

Bellenger, M., D. Fields, K. Tilt, and D. Hite. 2008. Producer preferences for migrant labor and the wage, hours, and gross sales effects in Alabama's horticulture industry. HortTechnology 18: 301-307.

Bryson, A., R. Dorsett, and S. Purdon. 2002. The use of propensity score matching in the evaluation of active labour market policies. 8 Sept. 2015. <http://eprints.lse.ac.uk/4993/1/ The_use_of_propensity_score matching_in_the_evaluation_of_active_ labour_market_policies.pdf>.

Campbell, B.L., R.M. Nayga, A. Silva, and J.L. Park. 2011 . Does the national school lunch program improve children's dietary outcomes? Amer. J. Agr. Econ. 93(4): 1099-1130.

Caplan, S., B. Tilt, G. Hoheisel, and T.A. Baugher. 2014. Specialty crop growers' perspectives on adopting new technologies. Hort Technology 24:81-87.

Cross, P., R.T. Edwards, B. Hounsome, and G. Edwards-Jones. 2008. Comparative assessment of migrant farm worker health in conventional and organic horticultural systems in the United Kingdom. Sci. Total Environ. 391(1):55-65.

Dehejia, R. and S. Wahba. 1999. Causal effects in non-experimental studies: Reevaluating the evaluations of training programs. J. Amer. Stat. Assn. 94(448): 1053-1062.

Foster, E.M. 2003. Propensity score matching: An illustrative analysis of dose response. Med. Care 41(10): 1183-1192.

Hall, C.R., A.W. Hodges, and M. Palma. 2011. Sales, trade flows and marketing practices within the US nursery industry. J. Environ. Hort. 29(1):14-24.

Heckman, J.J. and V.J. Hotz. 1989. Choosing among alternative nonexperimental methods for estimating the impact of social programs: The case of manpower training. J. Amer. Stat. Assn. 84(408):862-874.

Heckman, J.J., H. Ichimura, and P.E. Todd. 1997. Matching as an econometric evaluation estimator: Evidence from evaluating a job training programme. Rev. Econ. Stud. 64(4):605-654.

Hirano, K. and G.W. Imbens. 2001. Estimation of causal effects using propensity score weighting: An application to data on right heart catheterization. Health Serv. Outcomes Res. Methodol. $2(3-4): 259-278$.

Hitt, L.M. and E.M. Snir. 1999. The role of information technology in modern production: Complement or substitute to other inputs. 8 Sept. 2015. <https:// www.researchgate.net/profile/Eli_Snir/ publication/228540589_The_role_of_ information_technology_in_modern_production_ complement_or_substitute_to_other_inputs/ links/0deec52ebd48580b76000000.pdf $>$.

Hodges, A.W., C.R. Hall, and M. Palma. 2011. Economic contributions of the green industry in the United States in 2007-08. HortTechnology 21:628-638.

Jones, R. 2013. The even-higher-techfuture of the top 100 grower. 12 Sept. 2015. <http://www.greenhousegrower. $\mathrm{com} /$ top-100/the-even-higher-techfuture-of-the-top-100-grower $/>$. 
Jupe, M.K. and C.R. Hall. 2002. The impact of information technology on green industry marketing. Southern Nursery Assn. Res. Conf. 47:512-516.

Katchova, A.L. 2010. Agricultural contracts and alternative marketing options: A matching analysis. J. Agr. Appl. Econ. 42(2):261-276.

Mathers, H.M., A.A. Acuña, D.R. Long, B.K. Behe, A.W. Hodges, J.J. Haydu, U.K. Schuch, S.S. Barton, J.H. Dennis, B.K. Maynard, C.R. Hall, R. McNeil, and T. Archer. 2010. Nursery worker turnover and language proficiency. HortScience 45:71-77.

O'Keefe, S. 2004. Job creation in California's enterprise zones: A comparison using a propensity score matching model. J. Urban Econ. 55(1):131-150.
Posadas, B. 2012. Economic impacts of mechanization or automation on horticulture production firms sales, employment, and workers' earnings, safety, and retention. Hort Technology $22: 388-401$.

Posadas, B.C., P.R. Knight, C.E.H. Coker, R.Y. Coker, and S.A. Langlois. 2014. Hiring preferences of nurseries and greenhouses in U.S. southern states. HortTechnology 24:107-117.

Preibisch, K. 2010. Pick-your-own labor: Migrant workers and flexibility in Canadian agriculture. Intl. Migr. Rev. 44(2): 404-441.

Rogaly, B. 2008. Intensification of workplace regimes in British horticulture: The role of migrant workers. Popul. Space Place 14(6):497-510.
Rosenbaum, P.R. and D.B. Rubin. 1984. Reducing bias in observational studies using subclassification on the propensity score. J. Amer. Stat. Assn. 79(387):516524.

Rosenbaum, P.R. 2002. Observational studies. 2nd ed. Springer-Verlag, NewYork, NY.

U.S. Department of Agriculture. 2007. Table 61. Summary by type of organization: 2007. 2007 Census, Vol. 1, Chapter 1: U.S. National level data. 5 Sept. 2015. <http://www.agcensus.usda.gov/ Publications/2007/Full_Report/ Volume_1,_Chapter_1_US/st99_1_061_ 061.pdf>. 